\title{
One-dimensional lanthanide chain bridged by nitronyl nitroxide radical ligand: structure and magnetic properties
}

\author{
Hui Yang Dong and Me Zhu* \\ Department of Chemistry, Zhejiang Sci-Tech University, Hangzhou, Zhejiang, 310018, China
}

\begin{abstract}
In order to synthesize the molecular magnetic material, the complex $\left\{\mathrm{Nd}(\mathrm{hfac})_{3}(\mathrm{NIT}-\right.$ 5MeThien) $\}$ n(NIT-5MeThien=2-(5-Methyl-2' -thienyl)-5--4,4,5,5-tetramethyl-imidazoline-1-oxyl-3-oxide) has been synthesized by the reaction using radical ligand and $\mathrm{Nd}(\mathrm{hfac})_{3} \cdot 2 \mathrm{H}_{2} \mathrm{O}$. X-ray diffraction analysis showed that the compound belongs to the monoclinic system and constituted by $\mathrm{Nd}(\mathrm{hfac})_{3}$ and NIT$5 \mathrm{MeThien}$ to obtain a one-dimensional chain which nitroxide radical acted as a bridged ligand through the $\mathrm{N}-\mathrm{O}$ groups. Variable temperature magnetization of complex was shown the antiferromagnetic interaction between $\mathrm{Nd}(\mathrm{III})$ ion and nitroxide radical.
\end{abstract}

\section{Introduction}

Molecular ferromagnetic materials have gained increasing interest in the last three decades due to their high performance of magnetic properties. It has a wide range of applications, for example, high-density information storage; coating of stealth fighter and so on. ${ }^{[1-7]}$ The emergence of molecular-based materials began with the exploration of theory. First of all, McConnel ${ }^{[8]}$ propose that ferromagnetism can exsit in organic compounds and the mechanism of intermolecular ferromagnetic coupling. Meanwhile, the first molecularbased magnets $\left[\mathrm{Fe}(\mathrm{dtc})_{2} \mathrm{Cl}\right]$ were obtained by Wickman ${ }^{[9]}$. Then, more and more magnets were prepared by various methods. Among these ways, direct coordination of nitronyl nitroxide radicals to metal ions also has a place. Nitronyl nitroxide radical have played an important role in the design and synthesis of molecular magnets due to their nicer stability and easy to modify. A. Caneschi et al. ${ }^{[10]}$ first reported a one-dimensional chain molecular ferromagnet $\left[\mathrm{Ni}(\mathrm{hfac})_{2}(\mathrm{NITMe})\right]$. Magnetic studies show that there was a strong antiferromagnetic interaction between nickel and NO groups of nitronyl nitroxide radical. And subsequent research show that Ln ions have strong magnetoanisotropy ${ }^{[11-16]}$, so lanthanide-mangets have attracted attention from researchers.

In this paper, we design a new nitronyl nitroxide radical NIT-5MeThien (Scheme 1), and gained $\left[\mathrm{Nd}(\text { hafc })_{3}\right.$ (NIT-5MeThien) $]$ by using this nitronyl nitroxide radical to react with $\mathrm{Nd}$ (III) ion. The variabletemperature magnetic susceptibility shown that the coordinated radical ligands and $\mathrm{Nd}(\mathrm{III})$ ion exist antiferromagnetic couplings.

\footnotetext{
* Corresponding author: zhumei0321@163.com
}

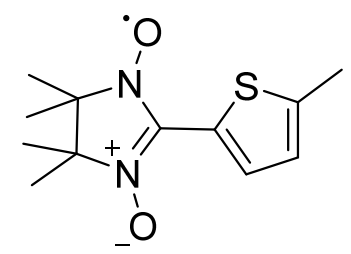

Scheme 1 NIT-5MeThien

\section{Experimental section}

\subsection{Materials and physical measurements}

All the chemical reagents used in the experiment were analytically pure, NIT-5MeThien were synthesized based on methods in the literature. ${ }^{[17]}$ Perkin-Elmer 240 elemental analyzer was used for element analyses $(\mathrm{C}, \mathrm{H}$ and $\mathrm{N}$ ). Infrared spectra data was derived from Bruker TENOR 27 spectrometer in the range of 400 to $4000 \mathrm{~cm}$ 1 (KBr pellets). Powder X-ray diffraction (PXRD) data of complex was obtained by a Rigaku Ultima IV diffractometer.

\subsection{Synthesized of [Nd(hafc) $)_{3}(\mathrm{NIT}-5 \mathrm{Me}$ Thien)]}

The complex is synthesized according to the following process. $\mathrm{Nd}(\text { hafc })_{3} \cdot 2 \mathrm{H}_{2} \mathrm{O}(0.02 \mathrm{mmol})$ was dissolved in boiling dry $\mathrm{n}$-heptane $(10 \mathrm{ml})$ and kept under reflux at $103{ }^{\circ} \mathrm{C}$ for two hours. Then the solution was cooled down to $90{ }^{\circ} \mathrm{C}$, after which a solution of NIT-5MeThien $(0.002 \mathrm{mmol})$ in $5 \mathrm{~mL}$ of $\mathrm{CH}_{2} \mathrm{Cl}_{2}$ was introduced slowly. The mixture solution keep stirring for $15 \mathrm{~min}$ at $90{ }^{\circ} \mathrm{C}$. After that, the mixture solution was cooled down to room temperature and filtered. Two days later, the green bars crystals which was suitable for X-ray diffraction was obtained. 
$\left[\mathrm{Nd}(\text { hafc })_{3}\right.$ (NIT-5MeThien) $] \quad$ Yield $46 \%$; $\mathrm{C}_{27} \mathrm{H}_{20} \mathrm{~F}_{18} \mathrm{~N}_{2} \mathrm{NdO}_{8} \mathrm{~S}$; Elem. anal. (\%) found: C, 31.46; $\mathrm{H}$, 2.13; N, 2.45; Calcd: C, 31.83; H, 1.98; N, 2.75. FTIR(KBr, cm-1): 3439 (w), 1654 (s), 1377 (w), 1350 (m), $1258(\mathrm{~s}), 1212(\mathrm{~s}), 1147(\mathrm{~s}), 802(\mathrm{~m}), 662(\mathrm{~m})$.

\subsection{X-ray data collection and structure refinement}

A Rigaku Saturn CCD diffractometer with graphitemonochromated Mo K $\alpha$ radiation $(\lambda=0.71073 \AA)$ at 173 $\mathrm{K}$ was used to get crystallographic data. The structure of compelx was solved by direct methods and refine by fullmatrix least-squares techniques against $\mathrm{F}^{2}$ with the SHELXS-97 and SHELXTL-97 ${ }^{[18-19]}$ program package. All hydrogen atoms were added geometrically at proper positions, and non-hydrogen atoms were refined anisotropically. Significant crystallographic data and structural refinement are included in Table 1. The important bond lengths $(\AA)$ and angles $\left(^{\circ}\right)$ are list in table 2 and table 3 .

Table 1. Crystallographic data and structure refinement for complex

\begin{tabular}{|c|c|}
\hline Formula & $\mathrm{C}_{27} \mathrm{H}_{20} \mathrm{~F}_{18} \mathrm{~N}_{2} \mathrm{NdO}_{8} \mathrm{~S}$ \\
\hline Formula weight & 1018.76 \\
\hline $\mathrm{T}(\mathrm{K})$ & $113(2)$ \\
\hline$\lambda(\AA)$ & 0.71073 \\
\hline Crystal system & Monoclinic \\
\hline Space group & $\mathrm{P}_{21} / \mathrm{c}$ \\
\hline Unit cell dimensions & $\begin{array}{l}a=21.041(6) \AA \alpha=90 \mathrm{deg} . \\
b=17.417(4) \AA \beta= \\
116.250(4) \mathrm{deg} . \\
\mathrm{c}=22.667(6) \AA \gamma=90 \mathrm{deg} .\end{array}$ \\
\hline Volume $\left(\AA^{3}\right)$ & $7450(3)$ \\
\hline$Z$ & 8 \\
\hline $\begin{array}{l}\text { Calculated density } \\
\left(\mathrm{mg} / \mathrm{m}^{3}\right)\end{array}$ & 1.817 \\
\hline $\begin{array}{l}\text { Absorption coefficient } \\
\left(\mathrm{mm}^{-1}\right)\end{array}$ & 1.587 \\
\hline Crystal size $\left(\mathrm{mm}^{3}\right)$ & $0.23 \times 0.20 \times 0.18$ \\
\hline $\begin{array}{l}\theta \text { range for data } \\
\text { collection }\left(^{\circ}\right)\end{array}$ & 1.54 to 27.91 \\
\hline Unique reflns/ $R_{\text {int }}$ & $\begin{array}{l}75772 / 17706[\mathrm{R}(\mathrm{int})= \\
0.0634]\end{array}$ \\
\hline $\begin{array}{l}\text { Completeness to } \theta= \\
25.01\end{array}$ & $99.5 \%$ \\
\hline $\begin{array}{l}\text { Max. and min. } \\
\text { transmission }\end{array}$ & 1.000 and 0.851 \\
\hline Refinement method & $\begin{array}{l}\text { Full-matrix least-squares } \\
\text { on } F^{\wedge} 2\end{array}$ \\
\hline Goodness-of-fit on $F^{2}$ & 1.118 \\
\hline $\begin{array}{l}\text { Final } R \text { indices }[I> \\
2 \sigma(I)]\end{array}$ & $R 1=0.0579, w R 2=0.1667$ \\
\hline$R$ indices (all data) & $R 1=0.0695, w R 2=0.1753$ \\
\hline
\end{tabular}

Table 2. The important bond distances $(\AA)$ for complex

\begin{tabular}{ll}
\hline Bond & Dist. $(\AA)$ \\
\hline $\mathrm{Nd}(1)-\mathrm{O}(1)$ & $2.400(3)$ \\
$\mathrm{Nd}(1)-\mathrm{O}(2)$ & $2.416(3)$ \\
$\mathrm{Nd}(1)-\mathrm{O}(3)$ & $2.394(4)$ \\
$\mathrm{Nd}(1)-\mathrm{O}(4)$ & $2.431(3)$ \\
$\mathrm{Nd}(1)-\mathrm{O}(5)$ & $2.406(4)$ \\
$\mathrm{Nd}(1)-\mathrm{O}(6)$ & $2.453(3)$ \\
$\mathrm{Nd}(1)-\mathrm{O}(7)$ & $2.415(3)$ \\
$\mathrm{Nd}(1)-\mathrm{O}(8) \# 3$ & $2.481(3)$ \\
\hline
\end{tabular}

Table 3. The important angles $\left(^{\circ}\right)$ for complex

\begin{tabular}{ll}
\hline Angle & $\left({ }^{\circ}\right)$ \\
\hline $\mathrm{O}(7)-\mathrm{Nd}(1)-\mathrm{O}(1)$ & $95.46(12)$ \\
$\mathrm{O}(7)-\mathrm{Nd}(1)-\mathrm{O}(2)$ & $144.96(12)$ \\
$\mathrm{O}(7)-\mathrm{Nd}(1)-\mathrm{O}(3)$ & $78.81(12$ \\
$\mathrm{O}(7)-\mathrm{Nd}(1)-\mathrm{O}(4)$ & $73.94(11)$ \\
$\mathrm{O}(7)-\mathrm{Nd}(1)-\mathrm{O}(5)$ & $92.88(12)$ \\
$\mathrm{O}(7)-\mathrm{Nd}(1)-\mathrm{O}(6)$ & $72.08(12)$ \\
$\mathrm{O}(7)-\mathrm{Nd}(1)-\mathrm{O}(8) \# 3$ & $142.27(11)$ \\
$\mathrm{O}(1)-\mathrm{Nd}(1)-\mathrm{O}(8) \# 3$ & $107.04(11)$ \\
\hline
\end{tabular}

\section{Results and discussion}

\subsection{Description of the crystal structures}

Single crystal X-ray diffraction data manifest that complex was crystallize in the monoclinic space group $P 2{ }_{1} / c$. Figure 1 shows the structure which is onedimensional chain. As depicted in figure 1 , the $\mathrm{Nd}(\mathrm{III})$ mental ion is eight-coordinated by two NO units of two radicals and six oxygen atoms of three hfac anions. The Nd-O(radical) distance range from 2.394 to $2.476 \AA$, which is basically consistent with previous reports. ${ }^{[20]}$ The Orad-Nd-Orad angle is $142.27(11)^{\circ}$. The shortest Nd---Nd distance is $8.709 \AA$ in the chain, Figure 2 shows that the shortest interchain Nd---Nd separation is 11.190 $\AA$.

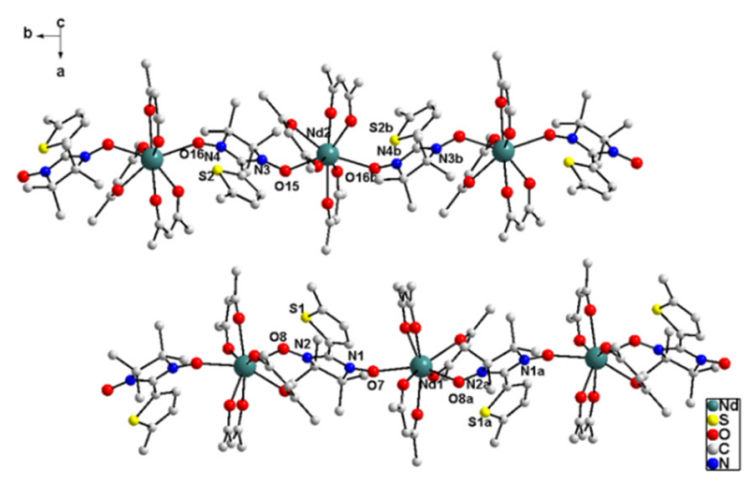

Figure 1. The structure of one-dimensional chain 


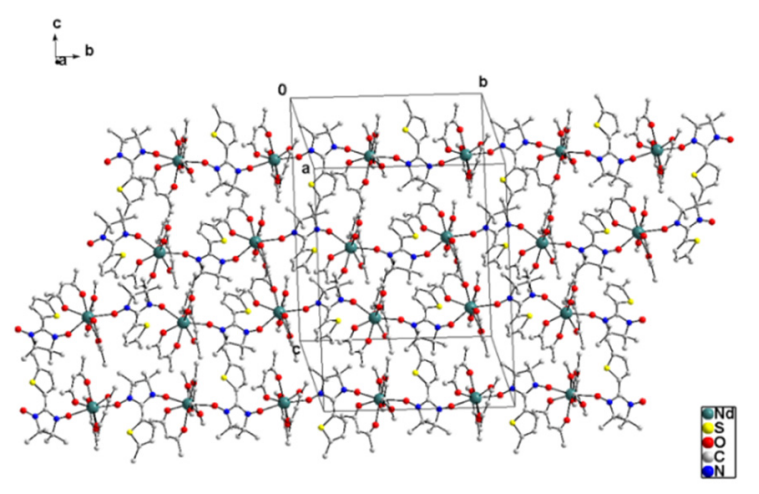

Figure 2. Packing of the chain in crystal for complex

\subsection{Magnetic properties}

The variable-temperature magnetic susceptibility data for complex was investigated under a dc field of $1000 \mathrm{Oe}$ at 2-300 K(figure 3). At room temperature, the value of $\chi_{M} \mathrm{~T}$ is $3.71 \mathrm{~cm}^{3} \mathrm{~K} \mathrm{~mol}^{-1}$. It is slightly lower than 4.03 $\mathrm{cm}^{3} \mathrm{~K} \mathrm{~mol}^{-1}$ which is the theoretical value of spin alone for two uncoupled $\mathrm{Nd}(\mathrm{III})$ ions $\left({ }^{4} \mathrm{I} 9 / 2\right)$ and two uncoupled radicals $(S=1 / 2)$. As temperature goes down, the value of $\chi_{M} \mathrm{~T}$ achieves a minimum of $0.96 \mathrm{~cm}^{3} \mathrm{~K}$ $\mathrm{mol}^{-1}$ at $2 \mathrm{~K}$. The reason why $\chi_{M} \mathrm{~T}$ decreases with temperature is that the exchange coupling between the $\mathrm{Nd}$ (III) ion and the NO radicals is antiferromagnetic. In the temperature range of $45-300 \mathrm{~K}$, the relationship between $\chi_{M}{ }^{-1}$ and $\mathrm{T}$ conforms to the Curie-Weiss law. Subsequently, a negative Weiss constant of $\theta=-19.65 \mathrm{~K}$ and the Curie constant of $\mathrm{C}=3.58 \mathrm{~cm}^{3} \mathrm{~K} \mathrm{~mol}^{-1}$ can be calculated by linear fitting. These data further proved that there is an antiferromagnetic interaction between the rare earth $(\mathrm{Nd}(\mathrm{III}))$ ion and the ligand $(\mathrm{NO})$.

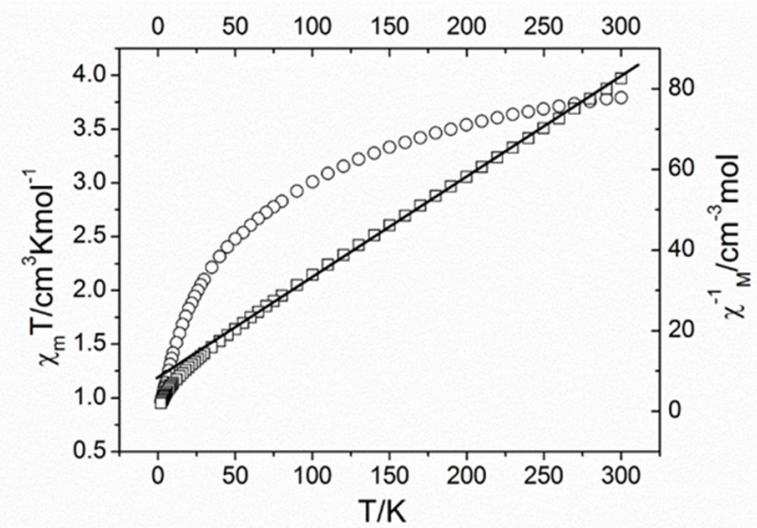

Figure 3. Plots of $\chi_{M} \mathrm{~T}$ vs. T and $\chi_{M^{-1}}$ vs. T for complex

\section{Conclusions}

In summary, we have successfully obtained onedimensional chain molecular magnets. In this complex, $\mathrm{Nd}$ (III) ions are bridged by nitronyl nitroxide radicals through the NO groups. The magnetic studies show that there is antiferromagnetic between $\mathrm{Nd}(\mathrm{III})$ ions and $\mathrm{NO}$ groups of nitronyl nitroxide radical.

\section{Acknowledgements}

This work was supported by the National Natural Science Foundation of China (No. 21701142) and Natural Science Foundation of Zhejiang Province (No. LQ17B010005).

\section{References}

1. Miller, J. S., Gatteschi, D. (2011) Molecule-based magnets. Chem. Soc. Rev., 40: 3065-3066.

2. Troiani, F., Affronte, M. (2011) Molecular spins for quantum information technologies. Chem. Soc. Rev., 40: 3119-3129.

3. Aromi, G., Aguila, D., Gamez, P., Luis, F., Roubeau, O. (2012) Design of magnetic coordination complexes for quantum computing. Chem. Soc. Rev., 41: 537-546.

4. Woodruff, D. N., Winpenny, R. E. P., Layfield, R. A. (2013) Lanthanide Single-Molecule Magnets. Chem. Rev., 113: 5110-5148.

5. Bogani, L., Wernsdorfer, W. (2008) Molecular spintronics using single-molecule magnets. Nat. Mater., 7: 179-186.

6. Caneschi, A., Gatteschi, D., Lalioti, N., Sangregorio, C., Sessoli, R., Venturi, G., Vindigni, A., Rettori, A., Pini, M. G., Novak, M. (2001) Cobalt(II)-Nitronyl Nitroxide Chains as Molecular Magnetic Nanowires. Angew. Chem., Int. Ed., 40: 1760-1763.

7. Zhang, W. X., Ishikawa, R., Breedlove, B., Yamashita, M. (2013) Single-chain magnets: beyond the Glauber model. RSC Adv., 3: 3772-3798.

8. McConnel, H. (1963) Ferromagnetism in Solid Free Radicals. J. Chem. Phys. 39: 1910-1919.

9. Wickman, H. H., Trozzolo, A. M., Williams, H. J., Hull G. W., Merritt, F. R. (1967) Spin-3/2 Iron Ferrimagnet: Its Mossbauer and Magnetic Properties. Phys. Rev, 155: 563-575.

10. Caneschi, A., Gatteschi, D., Renard, J. P. (1989) Magnetic Coupling in Zero- and One-Dimensional Magnetic Systems Formed by Nickel(II) and Nitronyl Nitroxides. Magnetic Phase Transition of a Ferrimagnetic Chain. Inorg. Chem. 28: 2940-2944.

11. McClain, K. R., Gould, C. A., Chakarawet, K., Teat, S. J., Groshens, T. J., Long, J. R., Harvey, B. G. (2018) High-temperature magnetic blocking and magneto-structural correlations in a series of dysprosium(III) metallocenium single-molecule magnets. Chem. Sci., 9: 8492-8503.

12. Guo, F. S., Day, B. M., Chen, Y. C., Tong, M. L., Mansikkamaki, A., Layfield, R. A. (2018) Magnetic hysteresis up to 80 kelvin in a dysprosium metallocene single-molecule magnet. Science, 362: 1400.

13. Xiao, Z. X., Miao, H., Shao, D., Wei, H. Y., Zhang, Y. Q., Wang, X. Y. (2018) Single-molecule magnet behaviour in a dysprosium-triradical complex. Chem. Commun., 54: 9726-9729. 
14. Ishikawa, N., Sugita, M., Ishikawa, T., Koshihara, S.Y., Kaizu, Y.(2003) Lanthanide double-decker complexes functioning as magnets at the singlemolecular level. J. Am. Chem. Soc., 125, 86948695.

15. Goodwin, C. A. P., Ortu, F., Reta, D., Chilton, N. F., Mills, D. P. (2017) Molecular magnetic hysteresis at 60 kelvin in dysprosocenium. Nature, 548, 439-442.

16. Guo, F. S., Day, B. M., Chen, Y. C., Tong, M. L., Mansikkamaki, A. Layfield, R. A. (2017) A Dysprosium Metallocene Single-Molecule Magnet Functioning at the Axial Limit. Angew. Chem., Int. Ed., 56, 11445-11449.

17. Ullman, E. F., Call, L., Osiecki, J. H. (1970) Stable Free Radicals. VIII. New Imino, Amidino, and Carbamoyl Nitroxides. J. Org. Chem., 35: 36233631.

18. Sheldrick, G. M. (1997) SHELXS 97, Program for the Solution of Crystal Structures. University of Götingen. Göttingen, Germany.

19. Sheldrick, G. M. (1997) SHELXL 97, Program for the Solution of Crystal Structures. University of Götingen. Göttingen, Germany.

20. Hu, P., Wang, X. F., Ma, Y., Wang, Q. L., Li, L. C., Liao, D. Z. (2014) A new family of Ln-radical chains $(\mathrm{Ln}=\mathrm{Nd}, \mathrm{Sm}, \mathrm{Gd}, \mathrm{Tb}$ and Dy): synthesis, structure, and magnetic properties. Dalton Trans., 43: 2234-2243. 